\title{
EDUCAÇÃO PARA A DIVERSIDADE NUMA PERSPECTIVA INTERCULTURAL*
}

\section{INTERCULTURAL PERSPECTIVE OF AN EDUCATION FOR DIVERSITY}

\author{
Maria Conceição Coppete ${ }^{* *}$ \\ Coautores: Reinaldo Matias Fleuri*** \\ e Tania Stoltz ${ }^{* * * *}$
}

Resumo: O artigo analisa a possibilidade de uma educação para a diversidade numa perspectiva intercultural. Está relacionado a uma pesquisa em nível de doutorado, defendida no ano de 2012 na Universidade Federal de Santa Catarina. As discussões apresentadas referem-se a um capítulo da tese. Destaca o conceito de diversidade no campo normativo, passando pelas ciências sociais e alcançando sua dimensão cultural, uma vez que, no Brasil, a expressão diversidade tem sido usada como multiculturalismo, principalmente pelo poder público revelando distintas proposições. Apresenta o conceito de educação intercultural e suas implicações na prática pedagógica. Dentro dessa abordagem, culturas diferentes são entendidas como contextos complexos e a relação entre elas produz confrontos entre visões de mundo diferentes. Essa educação favorece a construção de um projeto comum, mediante o qual é possível integrar dialeticamente as diferenças. Sua orientação está focada na construção de uma sociedade plural, democrática e eminentemente humana, capaz de articular políticas de igualdade com políticas de identidade.

Palavras-chave: Diversidade. Educação Intercultural. Prática Pedagógica. 
Abstract: This article examines the possibility of an education for diversity in an intercultural perspective. It is related to a research at doctorate level defended at the Federal University of Santa Catarina, in 2012. The discussion presented refers to a chapter of the thesis. Highlights the concept of diversity in the legal field, passing over social sciences and reaching its cultural dimension, as in Brazil, the term diversity has been used as multiculturalism, mainly by the government, revealing distinct propositions. Within this approach, different cultures are understood as complex contexts and the relationship between them produces clashes between different worldviews. This education favours building a common project through which it is possible to integrate dialectical differences. Its guidance is focused on building a pluralistic, democratic and eminently human society, capable of articulating equality policies with identity policies.

Keywords: Diversity. Intercultural Education. Pedagogical Practice. 
Cometemos um erro bastante comum ao pensar que ignoramos algo por sermos incapazes de defini-lo [...], diremos talvez que só podemos definir algo quando nada soubermos a respeito dele. Jorge Luis Borges

\section{Diversidade: um conceito emblemático e plural}

A diversidade vem se constituindo como um dos principais fatores de visibilidade nos contextos educacionais. Sua presença tem sido notória no palco dos debates relacionados à educação no país, principalmente nos últimos dez anos. No campo normativo, várias leis foram sancionadas, tais como a Lei n. 10.639/03, que torna obrigatório o ensino da história e da cultura afrobrasileira e africana em todas as escolas do país; e a Lei n. 11.645/08, que insere a questão indígena nos currículos escolares. Em relação ao Ministério da Educação (MEC), criou-se no ano de 2004 uma secretaria específica, a Secretaria de Educação Continuada, Alfabetização e Diversidade (SECAD), com o objetivo de articular o tema da diversidade nas políticas educacionais, entre outros.

Na literatura é possível identificar um conjunto variado e complexo de significados para o termo diversidade, conforme o campo ao qual se situa. Nas ciências sociais, geralmente o termo é empregado para tratar a heterogeneidade de culturas fortemente marcada na sociedade contemporânea. Essa posição se contrapõe ao modelo de Estado-nação moderno, liberal e ocidental, constituído “[...] sobre o pressuposto (geralmente tácito) da homogeneidade cultural organizada em torno de valores universais, seculares e individuais." (HALL, 2003, p. 52). Na sua dimensão cultural en- 
contra-se associada aos novos movimentos sociais, fundamentalmente aqueles de caráter identitário, circunscritos em torno da defesa das "políticas de diferença” (TAYLOR, 1994; GIROUX, 1999; HALL, 2003). Para Moehlecke (2009), tal reivindicação no Brasil decorreu de setores relacionados ao movimento feminista e ao movimento negro dos anos de 1980, tornando-se mais intensa nos anos seguintes, quando outros grupos passaram a fazer parte, como o dos movimentos indígenas e das pessoas com deficiência.

O diálogo estabelecido com essas questões é associado aos $\mathrm{Cul}$ ture Studies e aos estudos pós-coloniais. Para as teorias que abordam essas perspectivas, todos os seres humanos são igualmente dignos de respeito, reforçando assim a semelhança entre eles. O princípio da diferença questiona justamente a neutralidade e a efetividade dessa igual dignidade, ao afirmar que a identidade particular de um indivíduo ou grupo é ignorada, distorcida e forçada a se conformar a uma cultura dominante hegemônica que não a sua, atribuindo-lhe uma cidadania de segunda classe. Desse modo, apenas as minorias e povos não ocidentais são alienados de sua cultura e valores, o que torna as sociedades ocidentais cegas à diferença, por suprimirem a identidade, como também altamente discriminatórias, diz Moehlecke, a partir de Taylor (2009). Consequentemente, diz a mesma autora, entende-se que a luta pelo direito à diferença deve passar primeiro pela desconstrução da autoimagem negativa atribuída pelos colonizadores a diferentes povos.

Considerando as políticas públicas no Brasil, principalmente a partir do final dos anos de 1990, constata-se a preocupação com a diversidade cultural, especialmente quando articuladas ao gênero, raça e etnia. Essa preocupação se evidencia em relação às políticas educacionais, dentre as quais se pode citar como exemplo a 
incorporação da pluralidade cultural como tema transversal nos Parâmetros Curriculares Nacionais; a definição de um capítulo específico para abordar a educação especial; assim como os artigos voltados à educação indígena na Lei de Diretrizes e Bases da Educação Nacional LDB - n. 9.394/96; o Plano Nacional de Educação de 2001, com capítulos destinados à educação especial e educação indígena; a definição do dia 20 de novembro como dia da Consciência Negra; além das leis Lei n. 10.639/03 e Lei n. 11.645/08, já citadas e comentadas anteriormente.

No que se refere aos estudos acadêmicos com análises teóricas acerca da diversidade cultural na formulação de políticas públicas, o que se encontra é recente e com baixo volume de produção (SANSONE, 1998; MELO, 1999). Em relação à temática diversidade e educação, a produção é mais expressiva (MCLAREN, 1997; TOURAINE, 1998; SCHERER-WARREN, 1998, 2000; NANNI, 1998; FALTERI, 1998; FLEURI, 1998a, 2000, 2000a, 2001, 2002, 2003, 2005; GONÇALVES; SILVA, 1998, 2003; CANDAU, 2000, 2002, 2003, 2006; STOER, 2001; MOREIRA; SILVA, 2002; FLEURI; COSTA, 2001; FLEURI; GAUTHIER; GRANDO, 2001; PADILHA, 2004; SOUZA, 2002a). Nessas referências, os conceitos mais abordados são de pluralismo cultural, multiculturalismo e interculturalidade ao invés de diversidade cultural, especificamente, quando se trata da referência às variadas maneiras de interpretar como se dá a interação entre grupos sociais e suas culturas.

No Brasil, a expressão diversidade tem sido usada como multiculturalismo, principalmente pelo poder público. Este substantivo, de acordo com Hall (2003), refere-se às estratégias políticas empregadas para lidar com situações de diversidade desencadeadas em sociedades culturalmente plurais. Aliás, é preciso dizer que no âmbito educacional 
o termo (multiculturalismo) tem sido abordado com frequência e com sentidos bastante diversos. No que se refere aos variados tipos de multiculturalismo encontram-se, principalmente, os estudos de McLaren (2000), Giroux (1999) e Hall (2003).

Considerando o amplo conjunto de estudos relacionados a essa questão, é possível identificar, segundo Moehlecke (2009), três aspectos que delimitam e diferenciam os significados oscilantes associados ao multiculturalismo: o primeiro deles diz respeito ao reconhecimento ou não das hierarquias de poder presentes nas relações entre os diferentes grupos culturais; o segundo aspecto associa-se a uma visão mais essencializada ou mais dinâmica da identidade cultural de determinados grupos; e o terceiro está mais voltado à articulação ou não entre as desigualdades socioeconômicas e as diferenças culturais.

Para além da defesa desta ou daquela proposição, o fato é que as questões relacionadas com a diferença e a identidade cultural são candentes para a educação, principalmente no âmbito das escolas e, por conseguinte, das práticas pedagógicas.

Reinaldo Matias Fleuri (2009) destaca que no âmbito da educação a multiplicidade de termos e de concepções em torno de uma mesma ideia - multicultural, transcultural, intercultural - parece dificultar a compreensão do fenômeno. Nesse sentido, o autor questiona o significado desses conceitos e os contextos nos quais se aplicam. Destaca o intenso debate que acontece atualmente em torno da relação entre os diversos grupos culturais, mostrando a coexistência de variadas propostas e concepções que empregam termos iguais para designar conceitos diferentes, ou fazem afirmações idênticas mediante termos distintos. $\mathrm{O}$ conceito de educação multicultural é um exemplo importante. De acordo com Fleuri (2009, p. 37), o conceito de educação multicultural 
“[...] utilizado nos países anglo-saxônicos para designar a luta pela paridade de direitos entre diferentes grupos sociais e culturais na sociedade, na Europa é habitualmente traduzido pelo conceito de 'educação intercultural"'

A educação multicultural pode ser abordada sob duas perspectivas. A primeira como movimento em prol da equidade social, argumenta Fleuri (2009). O autor cita como exemplo o movimento das chamadas cidades educativas.

$1^{\text {a }}$. como movimento em favor de igualdade de oportunidades educacionais e de equidade (justiça) e contra toda sorte de discriminação e preconceito. O movimento recente das chamadas 'cidades educativas' encontra-se nessa linha de atuação. As 'cidades educativas' (poder local) conscientes do papel e da responsabilidade das cidades no que se refere à educação, além de desenvolver suas funções tradicionais (econômica, social, política e prestação de serviços), procuram desenvolver uma função especificamente educadora. Esse movimento baseia-se no fato de que conhecemos o mundo, primeiro através dos nossos pais, do nosso círculo imediato e só depois é que, progressivamente, alargamos nosso universo. O bairro, e logo em seguida, a cidade, são os principais meios educativos de que dispomos. A cidade educativa é uma cidade com personalidade própria, integrada a um país e ao mundo, um sistema complexo em constante evolução. (FLEURI, 2009, p. 37, grifos e aspas no original).

A segunda perspectiva contempla uma abordagem curricular como contraposição alternativa à abordagem monocultural ainda vigente. Tanto essa perspectiva, quanto a primeira sugerem um caráter enunciativo e propositivo.

$2^{\text {a }}$. como uma abordagem curricular. Nos recentes estudos no campo da Educação Comparada ou Internacional, o tema da educação multicultural vem sendo abordado. Há 
uma preocupação na Europa, por exemplo, em salvar da extinção numerosas línguas faladas. Os jovens preferem a língua usada pela mídia à sua língua materna. A alfabetização bilíngue seria uma forma de fazer frente a essa eutanásia cultural. Daí a necessidade de um currículo multicultural frente ao currículo monocultural atual. (GADOTTI apud FLEURI, 2009, p. 37, grifos no original).

A expressão "educação inter/multicultural” é utilizada pelos autores Stephen Stoer e Luísa Cortezão, da Universidade do Porto (Portugal), como forma de se referirem ao conjunto de movimentos que propõem não só o respeito mútuo às especificidades de cada grupo cultural, mas também a relação e a interação entre eles (FLEURI, 2009). O termo "transcultural” está relacionado à ideia de encontrar os valores que sejam comuns às diferentes culturas e que possibilitem criar uma base de entendimento que considere essas espeficidades.

[...] refere-se à idéia de encontrar os valores comuns das diferentes culturas que permitem criar uma base de entendimento, tendo em conta essas mesmas especificidades culturais. É um conceito que se refere especialmente aos processos de miscigenação que ocorrem na inter-relação entre diferentes grupos sociais e onde se trabalha com as zonas de fronteira, os "entrelugares" (Bhabha, 1998), que se constituem entre os diferentes movimentos e sujeitos. (FLEURI, 2009, p. 38).

\section{Educação Intercultural: considerações necessárias}

Para melhor compreender no que consiste a abordagem de educação na perspectiva intercultural, é importante saber o contexto de surgimento da expressão intercultura. 
O termo Intercultura, segundo Paola Falteri ${ }^{1}$ (1998), vem sendo utilizado pelo Conselho Europeu desde a década de 1980, quando foi decidido tratar a questão da entrada dos estrangeiros nas escolas; também foi adotado como perspectiva unificadora pelas 'educações', as quais, das mais variadas maneiras, focalizam a importância da convivência. De acordo com a autora, é um caso raro de escolha terminológica, uma vez que a expressão foi eleita em concordância entre os organismos oficiais e as bases. No plano educacional, a interculturalidade sinaliza um projeto cujo objetivo é a intervenção nas mudanças induzidas a partir do contato e da interação entre sujeitos e sua diversidade, de maneira que promova atitudes abertas ao confronto e conduza processos integradores entre culturas. Nessa mesma direção segue Del Arco Bravo (1998), ao dizer que quando duas ou mais culturas entram em contato, a impregnação que se produz é inevitável.

Cabe destacar os sistemáticos estudos realizados pelo grupo de pesquisa Mover ${ }^{2}$, sob a coordenação do professor doutor Reinaldo Matias Fleuri, que há 15 anos têm ampliado e aprofundado sucessivas pesquisas ${ }^{3}$ acerca das diferentes concepções de educação intercultural ou multicultural. Nos estudos realizados pelo grupo, Fleuri (1998) apresenta, inicialmente, esses termos como sinônimos. Posteriormente, considerando mais especialmente o contato com as pesquisas italianas sobre educação intercultural (NANNI apud FLEURI, 2009) a equipe passa a redimensionar tais conceitos entendendo-os como distintos. A educação intercultural é entendida como aquela que enfatiza a relação entre sujeitos culturais diferentes, enquanto a educação multicultural constituiria uma perspectiva que busca o reconhecimento identitário das minorias étnicas, em luta contra os processos de sujeição a que foram sub- 
metidas historicamente (FLEURI, 2000). Com o aprimoramento dos estudos, segundo Fleuri, amparando-se em Canen e Moreira (2009), ambos os conceitos são redimensionados:

\begin{abstract}
[...] o termo multiculturalidade passou a ser compreendido como indicador da realidade de coexistência de diversos grupos culturais na mesma sociedade, enquanto o termo interculturalidade servia para indicar o conjunto de propostas de convivência e de relação democrática e criativa entre culturas diferentes. Mais recentemente, interagimos com estudos que buscam representar polifonicamente a polissemia dos desafios e das propostas emergentes como as expressões inter/multicultural (utilizada por Stoer, 2001) e intertranscultural (utilizada por Padilha; 2004). (FLEURI, 2009, p. 39).
\end{abstract}

Em relação à problemática decorrente desse conjunto de conceitos (multi/inter/transculturalidade), Fleuri (2009), alerta sobre dois importantes aspectos a se considerar. O primeiro deles é a impossibilidade de reduzir a um único conceito o imenso conjunto de ideias, bem como de propostas que se encontram em elaboração neste campo de pesquisa e de ação educativa. Para o autor, a pluridade de perspectivas é fértil e rica, na medida em que demanda diálogo e compreensão mútua dos vários pontos de vista, de um lado e de outro. $\mathrm{O}$ segundo aspecto relevante diz respeito ao desafio no sentido de promover a unidade e a relação entre distintos grupos, sujeitos e culturas de maneira que tal unidade e relação não anulem as diferenças, mas sim sejam potencializadoras do desenvolvimento de cada um - este é o eixo fundamental da problemática que toda essa situação enuncia (FLEURI, 2003).

Nos estudos mais recentes realizados por Fleuri e seu grupo de pesquisa, vislumbra-se uma nova perspectiva epistemológica em 
relação às identidades e relações interculturais, como sendo híbridas e ambivalentes. Nesse sentido, o foco reside na busca de entender os "entrelugares" (BHABHA, 1998); ou seja, buscar o entendimento "[...] dos contextos intersticiais que constituem os campos identitários, subjetivos ou coletivos, nas relações e nos processos interculturais." (FLEURI, 2009, p. 39). Sendo assim, a intercultura se torna um objeto de estudo transversal, interdisciplinar e complexo às temáticas de cultura, de etnia, de gerações, de gênero, de movimento e de ação social.

Em Coppete (2007), explico que o prefixo inter marca a reciprocidade, a interação, o intercâmbio, a ruptura do isolamento e, concomitantemente, indica separação, interposição e diferença. Refere-se, portanto, a um processo dinâmico marcado pela intercessão de perspectivas que podem ser entendidas como representações sociais produzidas em interação. Para Muñoz Sedano (1997, p. 119), “[...] caracteriza uma vontade de mudança, de ação no contexto de uma sociedade multicultural." É um processo permanente e inacabado, fortemente marcado pela intenção de promover relações democráticas e dialógicas entre grupos e culturas diversas.

Fleuri, Coppete e Azibeiro (2009) destacam que o tema da interculturalidade tem sido cada vez mais recorrente, de moda, paradoxal; por sua contemporaneidade tem sido usado em variados contextos, prestando-se a interesses sociopolíticos diversos. Os movimentos sociais, a mídia, a pesquisa científica e os programas governamentais têm promovido o reconhecimento da diversidade multicultural, o que denota o interesse pela temática da interculturalidade. Porém, em algumas situações, tem se apresentado como uma nova tendência multicultural, isenta de sentido crítico, político, construtivo e de transformação. O que se constata é que 
o esforço pela promoção do diálogo e da cooperação crítica e criativa entre as pessoas e seus contextos distintos corre o risco de reeditar novas formas de sujeição e de subalternização. Os autores destacam duas perspectivas teórico-epistemológicas distintas. De um lado estão aquelas que reduzem as relações interculturais às relações individuais, desconsiderando os contextos sociopolíticos de subalternização. De outro lado, surgem perspectivas de interculturalidade crítica que apontam para a descolonialização do saber, do poder, do ser e do viver. Essa perspectiva conclama a elaboração e mobilização de formas de saber, poder, ser e viver que garantam a convivência de todos os seres humanos com a natureza e entre si, "para além de dispositivos e de estruturas de dominação sociocultural e de destruição sistemática da natureza vigentes no atual contexto mundial." (FLEURI; COPPETE; AZIBEIRO, 2009, p. 31).

Catherine Walsh (2009), na conferência de abertura proferida no XII Congresso da Association internationale pour la Recherche Interculturelle (ARIC) ${ }^{4}$, defendeu a perspectiva crítica de interculturalidade. Para a autora,
[...] interculturalidade em si, só terá significação, impacto e valor se assumida de maneira crítica, como ação, projeto e processo que procura intervir na re-fundação das estruturas [...] da sociedade que racializa, inferioriza e des- humaniza, [...] na matriz ainda presente da colonialidade do poder. (WALSH, 2009, p. 2).

Três perspectivas envolvem atualmente a interculturalidade: $r e$ lacional, funcional e crítica. Fleuri, Coppete e Azibeiro (2009) amparados em Walsh (2009) argumentam que a primeira perspectiva, designada como relacional, faz referência ao contato e intercâm- 
bio entre culturas diferentes, como sendo algo que existe há muito tempo. Essa perspectiva considera os processos de mestiçagem, os sincretismos e as transculturações como sendo naturais. Nessa perspectiva, existe uma forte tendência a ocultar ou minimizar os conflitos, assim como os contextos de poder e dominação; a relação é limitada ao nível individual. "Na medida em que encobre as estruturas sociais, políticas, econômicas e também epistêmicas, posiciona a diferença cultural em termos de superioridade ou inferioridade." (FLEURI; COPPETE; AZIBEIRO, 2009, p. 31). Em outras palavras, reduzem as relações interculturais às relações individuais, sem considerar os contextos sociopolíticos de subalternização.

A segunda perspectiva, chamada por Wash de funcional, e referendada pelos autores já citados, reconhece a diferença cultural com o objetivo de incluí-la na estrutura social estabelecida. Investe na promoção do diálogo, na convivência e na tolerância; todavia, não questiona as possíveis causas da assimetria e da desigualdade social e cultural. Adota a (nova) lógica multicultural do capitalismo global. Reconhece e sustenta a produção e administração da diferença de maneira funcional à expansão do sistema-mundo-moderno, destacam Fleuri, Coppete, Azibeiro, amparados em Quijano (2009). Aponta para o controle do conflito étnico, a partir da inclusão dos grupos historicamente excluídos, porém faz isso com vistas a manter a estabilidade social de acordo com os ditames econômicos do modelo neoliberal.

A terceira perspectiva, defendida por Walsh e autores já citados, como interculturalidade crítica, aponta para a construção de sociedades diferentes, a outra ordem social, na medida em que problematiza a estrutura colonial racial e sua ligação ao capitalismo de mercado. A abordagem traduz a reivindicação de povos e grupos 
sociais historicamente subalternizados; representa também setores de luta a eles associados, na construção de uma sociedade justa, equitativa, igualitária e plural. Trata-se, portanto, de um projeto de vida que implica formas de viver e estar neste mundo; um projeto político, social, ético e epistêmico.

Tais abordagens são citadas no sentido de apresentar os estudos mais atuais na área, assim como evidenciar e fortalecer a escolha pela abordagem de educação intercultural como opção téorico-metodológica mais coerente com as finalidades deste estudo.

\section{Implicações de uma educação de abordagem intercultural}

No que implica uma educação de abordagem intercultural? O objetivo maior dessa abordagem consiste em auxiliar as pessoas a se apropriarem do código que possibilita acessar o universo do outro, ou seja, os valores, a história, a maneira de pensar, de viver, entre outros. Uma vez que tenha acesso a esse código, poderá voltar ao seu próprio código, e seu universo pessoal estará mais enriquecido pela troca empreendida. Assim, é possível inferir que a educação intercultural sugere que as pessoas aprendam e se habituem a olhar, mediados por uma ótica diferente. Propõe mudanças cognitivas e emocionais que as levem a compreender como os outros pensam e sentem; e nesse processo retornem a si mesmos mais conscientes de suas próprias raízes culturais. Esses fatores remetem à sensibilidade no exercício da docência na medida em que afeta a diversidade, a alteridade, o cuidado, a afetividade, a capacidade criadora, entre outros aspectos que envolvem as ações humanas, como assevera Campani (1993). 
Nos processos de aprendizagem e nas relações sociais interculturais, os contatos são de reciprocidade e de trocas, afirma Vieira (1999). É preciso pensar em educação para o plural, no sentido atribuído por Certeau (2001) e discutido anteriormente; o que demanda a reestruturação de todo sistema de atitudes, o qual, segundo Vieira, é responsável pelas representações que cada pessoa faz dos outros. No dizer do autor é "metamorfosear a identidade pessoal" (CERTEAU, 2001, p. 20) trata-se de uma possibilidade de conviver com as diferenças.

A educação intercultural contempla uma abordagem emancipatória e rizomática, constituída na e pela percepção da multiplicidade de olhares, nas inter-relações, na interação entre as diversas culturas. Demanda, indubitavelmente, um encontro. Todavia, não se trata de um encontro pura e simplesmente entre pessoas diferentes. Para que um encontro seja intercultural, na forma como nesta pesquisa se defende e se procura, é significativo que as diferenças sejam como "tensões produtivas", como sugere Torres (1998), de onde se pode partir para a construção de conhecimentos e de práticas escolares e educativas que sejam relevantes para os vários grupos sociais envolvidos.

É fato que todas as culturas têm sua dinamicidade e nela se ressignificam. Assim, todas têm seus processos internos, o que lhes possibilita preservar suas singularidades, sua diversidade; concomitantemente, estabelecem relações e constituem vínculos com outras culturas, mediante processos de negociação que lhes possibilitam viver junto às demais. Nesse movimento, muitas vezes conflitivo, apropriam-se de aspectos dessas culturas, e nesse movimento reinventam a sua própria vida. Essas relações internas e externas estão diretamente relacionadas ao contexto e ao espaço onde cada cultura está inserida e se desenvolve. 
Numa perspectiva intercultural, a escola, como contexto institucional, possui um significado de extrema importância. É nela e por meio dela que crianças, jovens e adultos podem interagir de maneira criativa e, segundo Fleuri (1998), compartilhar processos formativos. Muitas e significativas contribuições decorrem da articulação entre propostas e experiências de educação, especialmente no âmbito da educação popular, mas também no âmbito da educação básica, assim como nos processos de formação de professores e professoras.

Dessa forma, considerar a diversidade numa perspectiva intercultural, tendo em vista os processos de formação de professores e professoras, pressupõe buscar maneiras de estabelecer novos relacionamentos que ultrapassem os limites da cultura local, possibilitando a sua exteriorização e o acesso a outras realidades culturais ${ }^{5}$. González Manjón (1993) destaca as principais características na organização das ações com vistas a favorecer a escola aberta à diversidade e, por conseguinte, às práticas educativas numa abordagem intercultural de educação. Para o autor, é necessário haver flexibilidade, funcionalidade, participação e comunicação.

A educação intercultural pressupõe primeiramente uma intencionalidade que motiva a relação entre grupos culturais diferentes, que também pode ser significada por objetivos em comum. Dessa forma, demanda um projeto educativo intencional capaz de promover essa relação. Uma segunda característica é que essa perspectiva entende e considera a relação entre as culturas na prática educativa como modos próprios de cada grupo ver e interagir com a realidade, como argumenta Fleuri (1999).

Dentro dessa abordagem, culturas diferentes são entendidas como contextos complexos e a relação entre elas produz confron- 
tos entre visões de mundo diferentes. Compartilho do entendimento de Fleuri (2001), ao dizer que a cultura constitui a trama da existência humana. Uma teia de significados. Interagir com uma cultura diferente "[...] contribui para que uma pessoa ou um grupo modifique o seu horizonte de compreensão da realidade na medida em que lhe possibilita compreender pontos de vista ou lógicas diferentes de interpretação da realidade ou de relação social." (FLEURI, 2001, p. 53). Uma terceira particularidade refere-se à ênfase dada aos sujeitos da relação, ou seja, a valorização é dada prioritariamente aos sujeitos que são os que criam e sustentam as culturas.

A educação intercultural se desenvolve como relação entre pessoas de diferentes culturas. Não se pode perder de vista que os sujeitos se formam em contextos culturais determinados; todavia são eles que fazem cultura. "A estratégia intercultural consiste antes de tudo em promover a relação entre as pessoas, enquanto membros de sociedades históricas, caracterizadas culturalmente de modo muito variado, nas quais são sujeitos ativos." (FLEURI, 2001, p. 53, grifos no original). Fleuri (2000a) cita Nanni para dizer que a educação intercultural se configura como um processo, um caminho aberto, complexo e multidimensional por envolver múltiplos fatores e dimensões, dentre os quais se destacam a pessoa e o grupo, a cultura e a religião, a língua e a alimentação, os preconceitos e as expectativas. A educação intercultural não pode ser reduzida e limitada a uma simples relação de conhecimento. “Trata-se da interação entre sujeitos. Isso significa uma relação de troca e de reciprocidade entre pessoas vivas, com rostos e nomes próprios, reconhecendo reciprocamente seus direitos e sua dignidade." (FLEURI, 2000a, p. 77). 
Concordo com as ideias apresentadas por Fleuri (1999), muito especialmente, quando diz que a educação intercultural se configura como uma "pedagogia do encontro até suas últimas conseqüências", na medida em que busca promover uma experiência de caráter profundo e complexo na qual o encontro/confronto de distintas narrativas se configura como uma oportunidade singular de crescimento pessoal, e uma experiência viva, intensa e também singular de conflito/acolhimento. Trata-se, portanto, de um processo ambivalente, característico de uma relação intercultural, imprevisível em seu desdobramento; daí a necessidade de verificar se ocorre ou não o que ele nomeia de "transitividade cognitiva", que em outras palavras significa a produção de efeitos na própria matriz cognitiva do sujeito, desencadeada pela interação cultural. Compartilho do entendimento do autor ao dizer que esse processo "[...] constitui uma particular oportunidade de crescimento da cultura pessoal de cada um, assim como de mudança das relações sociais, na perspectiva de mudar tudo aquilo que impede a construção de uma sociedade mais livre, mais justa e mais solidária." E Fleuri (1999) mais uma vez recorre a Nanni para dizer que a educação intercultural é promotora de mudanças, inclusive no sistema escolar, já que "[...] defende a igualdade de oportunidades educacionais para todos, requer a formação dos educadores, estimula a reelaboração dos livros didáticos, assim como a adoção de técnicas e instrumentos multimediais." (FLEURI, 1999, p. 281). Todavia, não se pode perder de vista que se por um lado ela é promotora dessas grandes causas, por outro necessita encontrar um ambiente favorável à mudança, e em condições para isso. Em outras palavras, como destaca o autor, fazer acontecer a perspectiva intercultural de educação implica mudanças estruturais na prá- 
tica educativa, particularmente na escola, no sentido de assegurar oportunidades de educação para todas as pessoas, com respeito e reconhecimento da diversidade de sujeitos e de seus pontos de vista; o desenvolvimento de processos educativos, metodologias e instrumentos pedagógicos suficientemente capazes de abarcar a complexidade das relações humanas estabelecidas entre indivíduos e culturas diferentes; e a reinvenção do papel e do processo de formação de educadores. Reitero a assertiva feita acima, sobre a necessidade de se levar em conta que essas práticas demandam outro entendimento de escola, de sala de aula e de relações de ensino e aprendizagem, outra cosmovisão, radicalmente diferentes da concepção tradicional e hermética, erguida sob velhos pilares conservadores, sustentados por uma perspectiva monocultural e etnocêntrica, herdada do paradigma mecanicista/simplificador, insuficiente nos dias atuais.

A abordagem de educação intercultural contempla elementos do pensamento complexo, cuja dinamicidade é um de seus principais fatores. Podemos identificá-lo na capacidade de articular, integrar e refletir os distintos conhecimentos. O pensamento complexo procura restabelecer o diálogo entre formas simplificadas de pensar - características do paradigma simplificado - e formas sistêmicas de compreender - paradigma da complexidade - unidade não é o oposto da diversidade, tampouco quantidade é oposta à qualidade. Moraes (2003) diz tratar-se de um novo olhar, cujo foco está na articulação capaz de ajustar a ação e o pensamento do sujeito sobre o objeto. É uma condição necessária já que o novo século no qual vivemos submete a educação a uma dura obrigação. "À educação cabe fornecer, de algum modo, os mapas de um mundo complexo e constantemente agitado, e, ao mesmo tempo, a bússola 
que permita navegar através dele." (DELORS, 1996, p. 89). A educação em sua perspectiva intercultural pode ser um indicador de caminhos possíveis, sugerindo outras direções possíveis, que pedem, por conseguinte, outra docência, capaz de construir pontes, outras margens e desvãos, como argumentei anteriormente.

Desde logo, e amparada nos autores Fleuri (1998, 2001, 2002, 2003, 2005, 2009), Candau (1997, 2000, 2006, 2008), Walsh (2009), Falteri (1998) e em estudos desenvolvidos e publicados em Coppete (2003, 2003a, 2007), entendo que a educação intercultural é um processo cuja premissa básica reside na promoção deliberada da inter-relação crítica e solidária entre distintos grupos culturais existentes em uma determinada sociedade. Valoriza a explicitação da riqueza e da potencialidade das diferenças culturais. Concebe as culturas em contínuo processo de construção e de reconstrução, ou seja, em permanente processo de elaboração, na medida em que entende que as raízes subjacentes a cada cultura são históricas e dinâmicas, razão pela qual não fixam as pessoas em um determinado padrão cultural. Reconhece a intensidade inerente aos processos de hibridização cultural ${ }^{6}$ e o potencial que possuem como construtores de identidades abertas, sugerindo que não há pureza nas culturas. A perspectiva intercultural compreende que as relações culturais são construídas historicamente e se encontram fortemente atravessadas por relações hierarquizadas e de poder; relações cujo preconceito e cuja discriminação são fortemente demarcados, principalmente no que se refere a determinados grupos sociais. Essa perspectiva não desvincula as questões da diferença e da desigualdade que se dão a ver de maneira tensa e conflitiva na atualidade, tanto no âmbito mundial, quanto em cada sociedade em particular; daí sua perspectiva crítica focada 
na descolonialização do saber, do poder, do ser e do viver. E como tal, conclama a elaboração e mobilização de formas de saber, poder, ser e viver que garantam a convivência de todos os seres humanos com a natureza e entre si.

A perspectiva intercultural afirma essa relação e confirma sua complexidade, admitindo distintas configurações de acordo com cada realidade. É promotora de uma educação que reconhece o outro e defende o diálogo entre os distintos grupos sociais e culturais. Volta-se para a negociação cultural e aposta no enfrentamento dos conflitos decorrentes da assimetria de poder existente entre os diferentes grupos presentes nas sociedades nas quais vivemos.

Essa educação favorece a construção de um projeto comum, mediante o qual é possível integrar dialeticamente as diferenças. Sua orientação está focada na construção de uma sociedade plural, democrática e eminentemente humana, capaz de articular políticas de igualdade com políticas de identidade.

A educação intercultural acontece quando é possível criar contextos educativos capazes de oportunizar a integração e a interação tanto criativa quanto cooperativa, crítica e afetiva entre diferentes sujeitos e diferentes contextos sociais e culturais; esta relação se constitui baseada na troca e na reciprocidade entre pessoas, transpondo a dimensão individual dos sujeitos e envolvendo pertencimentos e identidade ${ }^{7}$.

A educação intercultural é um conceito de extrema potência, na medida em que amplia o olhar sobre o fazer pedagógico a partir da interação entre experiências realizadas em espaços distintos, mas que se tornam similares porque se retroalimentam e possibilitam reconstruções entre um aqui e um acolá, gestando um "entrelugar", diferente deste e daquele. Agir interculturalmente requer diálogo 
e compreensão mútua dos vários pontos de vista, de um lado e de outro. Seu objetivo é promover a unidade e a relação entre distintos grupos, sujeitos e culturas de maneira que tal unidade e tal relação não anulem as diferenças, mas que sejam potencializadores do desenvolvimento de cada um.

Assim posto, parece situar-se em um plano teórico e abstrato; todavia se olharmos desde os contextos de aprendizagem no interior das salas de aula, envolvendo substancialmente as relações que acontecem entre professor/a e educandos e educandos entre si, e mesmo entre professores e professoras e ainda entre esses/ as e as demais instâncias que compõem o coletivo da escola, essa abordagem adquire concretude e possibilidade efetiva de acontecer; relações que se estabelecem no interior das salas de aula e nas escolas de modo geral são sempre tensas, intensas e conflitivas, e revelam as concepções que se encontram subliminares às atitudes das pessoas.

No âmbito das ações docentes, e mais precisamente no terreno dos conteúdos escolares e das metodologias, a perspectiva intercultural inclui os processos de interação em sala de aula, onde a participação é dialógica e dinâmica, reflexiva e pró-ativa; onde os conflitos são entendidos como mobilizadores do processo de aprendizagem; a tomada de decisões não se dá arbitrariamente pelo professor e a professora; elas decorrem de processos de negociação entre os estudantes mediados pelos docentes; decisões potencializadoras do enriquecimento intercultural, ajustadas aos distintos interesses e capacidades, as quais podem ser aplicadas a outros contextos. A crítica e o aperfeiçoamento são favorecidos progressivamente; a cooperação é potencializada assim como a planificação de ações e o seu desenvolvimento. Nessa abordagem 
é fundamental que os sujeitos sintam-se pessoalmente comprometidos na análise das próprias atitudes e valores, na busca de novas perspectivas compartilhadas. Portanto, não está restrita à mera inserção de temas dentro do currículo ou de metodologias pedagógicas. Trata-se de uma nova perspectiva, e como tal requer novas relações, enfoques e procedimentos. Contempla uma proposta de transformação estrutural e sócio-histórica, na medida em que concebe a pedagogia como política cultural; daí seu caráter propositivo e não apenas denunciativo.

Pensar, agir e viver interculturalmente, especialmente a partir de uma perspectiva crítica, transpõe a descoberta de si mesmo e do outro; requer ações pensadas e executadas de maneira interativa, respeitosa, solidária, afetiva, prospectiva com vistas à justiça e equidade social; à construção de um mundo menos desigual.

Se é fato que o curso seguido pela vida humana é o da sensibilidade, e nela as nossas emoções interagem com nossas ideias e valores estabelecendo significados vivenciais para assim dizer a nós e aos outros quem somos, quem são nossos outros e o que estamos vivendo, experimentando e fazendo com eles e entre eles, como diz Carlos Rodrigues Brandão (2005), então também é fato que a educação intercultural é geradora de sensibilidade, na medida em que possibilita a reflexão associada à emoção; em outras palavras, as emoções são significadas por meio de saberes, de valores e de sentidos que criamos cooperativamente, para construir e compartilhar nossas vidas.

Para que projetos interculturais aconteçam é necessário, entre outros aspectos, articular políticas educativas e práticas pedagógicas comprometidas com o princípio da não discriminação e voltadas à desconstrução de subalternidades, à emancipação e à liberdade; às práticas efetivamente emancipatórias. 


\section{Referências}

BHABHA, Homi K. O local da cultura. Trad. Myriam Ávila, Eliana Lourenço de Lima Reis, Glaúcia Renate Gonçalves. Belo Horizonte: Ed. UFMG, 1998.

BRANDÃO, Carlos Rodrigues. Aprender o Amor: sobre um afeto que se aprende a viver. Campinas, SP: Papirus, 2005.

BRASIL. Lei de Diretrizes e Bases da Educação Nacional. Lei no 9.394, de 1996.

Plano Nacional de Educação - Lei 10.172, de 09 de janeiro de 2001. Aprova o Plano Nacional de Educação e dá outras providências. Brasília: Plano, 2001b. (Apresentado por Ivan Valente. Rio de Janeiro: DP\&A, 2001).

CAMPANI Giovanna. La educación intercultural: uma perspectiva pedagógica em Europa. In: GARCIA CASTAÑO, Francisco Javier. Educación multicultural. Granada: Universidade de Granada, 1993.

CANCLINI, Nestor Garcia. Consumidores e cidadãos: conflitos multiculturais da globalização. Rio de Janeiro: Editora UFRJ, 1995.

- Culturas Híbridas: estratégias para entrar e sair da modernidade. Trad. Ana Regina Lessa e Heloísa Pezza Cintrão. São Paulo: EDUSP, 1997.

CANDAU, Vera Maria. Pluralismo cultural, cotidiano escolar e formação de professores. In: (Org.). Magistério: construção cotidiana. Rio de Janeiro: Vozes, 1997. p. 237-250.

. Interculturalidade e Educação Escolar. In: (Org.). Reinventar a escola. Petrópolis: Vozes, 2000. p. 47-60.

(Org.). Sociedade, Educação e Cultura(s). Questões e propostas. Petrópolis:Vozes, 2002.

Somos todos iguais? Escola, discriminação e educação em direitos humanos. Rio de Janeiro: DP\&A, 2003. 
Direitos Humanos, Educação e Interculturalidade. 2006. Disponível em: <http://www.dhnet.org.br/educar/1congresso/072_ congresso_vera_candau.pdf $>$. Acesso em: 11 set./2011.

- Multiculturalismo e educação: desafios para a prática pedagógica. In: MOREIRA, Antônio Flávio; CANDAU, Vera Maria (Orgs.). Multiculturalismo: diferenças culturais e práticas pedagógicas. Petrópolis: Vozes, 2008. p. 13-37.

CERTEAU, Michel de. A Cultura no Plural. 2. ed. Trad. Enid Abreu Dobránszky. Campinas: Papirus, 2001.

COPPETE, Maria Conceição. Janelas Abertas: uma experiência de educação no Morro Mont Serrat Florianópolis. São Paulo: Secretariado Interprovincial Marista, 2003.

. De um lugar para viver a um lugar para construir. In: $26^{a}$ REUNIÃO ANUAL DA ANPED: NOVO GOVERNO. NOVAS POLÍTICAS? 5 a 8 de outubro de 2003. Anais... 2003a. Disponível em: $<$ www.anped.org.br/reunioes/26/trabalhos/mariaconceicaocoppete. $\mathrm{rtf}>$. Acesso em: 26 set. 2009.

- Da multiculturalidade à interculturalidade: percursos e processos. In: VALLEJO, Antonio Pantoja; ZWIEREWICZ (Orgs.). Sociedade da informação, educação digital e inclusão. Florianópolis. Insular, 2007.

DEL ARCO, Bravo. Isabel. Hacia una escuela intercultural. El profesorado: formación y expectativas. Lleida: Edicions Universitat de Lleida, 1998.

DELORS, Jacques (Coord.). Educação: um tesouro a descobrir. São Paulo: Cortez, 1996.

FALTERI, Paola. Interculturalismo e culturas no Plural. In: FLEURI, Reinaldo Matias (Org.). Intercultura e Movimentos Sociais. Florianópolis: Mover; NUP, 1998. p. 33-43.

FLEURI, Reinaldo Matias; GAUTHIER, Jacques; GRANDO, Beleni S. (Orgs.). Uma pesquisa sociopoética: o índio, o negro e o branco no 
imaginário de pesquisadores da área de educação. Florianópolis: UFSC/ NUP/CED, 2001.

FLEURI, Reinaldo M. Educação intercultural e movimentos sociais: considerações introdutórias. In: (Org.). Intercultura e Movimentos Sociais. Florianópolis: Mover; NUP, 1998. p. 9-27.

. Educação Intercultural no Brasil: a perspectiva epistemológica da complexidade. Revista Brasileira de Estudos Pedagógicos, Brasília, v. 80, n. 195, p. 277-289, maio/ago. 1998a.

. Desafios a educação intercultural no Brasil. In: III SEMINÁRIO PESQUISA EM EDUCAÇÃO REGIÃO SUL/ANPEd. Fórum Sul de Coordenadores de Pós-Graduação. Porto Alegre: Anais eletrônicos... 2000.

. Multiculturalismo e interculturalismo nos processos educativos. In: ENCONTRO NACIONAL DE DIDÁTICA E PRÁTICA DE ENSINO - ENDIPE. Ensinar e aprender: sujeitos, saberes e pesquisa. Rio de Janeiro: DP\&A, 2000a. p. 67-81.

- Desafios à educação intercultural no Brasil. Educação, Sociedade e Cultura, n. 16, p. 45-62, 2001.

- Educação intercultural: a construção da identidade e da diferença nos movimentos sociais. Perspectiva, Florianópolis, v. 20, n. 2, p. 405-423, jul./dez. 2002.

. Intercultura e Educação. Revista Brasileira de Educação, n. 23, p. 16-35, maio/ago. 2003.

. Palestra Proferida no V Colóquio Internacional Paulo Freire. 2005. Disponível em: <www.paulofreire.org.br/Textos/ fleuri_2005_ recife_resumo_e_texto_completo.pdf $>$. Acesso em: 8 nov. 2010.

O que significa Educação Intercultural. In: . Educação para a diversidade e cidadania. Módulo 2: Introdução Conceitual Educação para a Diversidade e Cidadania. Florianópolis: MOVER/ NUP/CED/EAD/UFSC, 2009. 
. Quinta Parte. In: ; COSTA, Marisa Vorraber. Travessia: questões e perspectivas emergentes na pesquisa em educação popular. Ijuí: Editora Unijuí, 2001. p. 91-107. (Coleção Livros de Bolsa).

; COPPETE, Maria Conceição; AZIBEIRO, Nadir E. In: OLIVEIRA, Lilian B. et al. (Orgs.). Culturas e Diversidade Religiosa na América Latina. Pesquisas e Perspectivas Pedagógicas. Blumenau: Editora Edifurb, 2009. p. 30-46.

GIROUX, Henry. A. Cruzando as Fronteiras do Discurso Educacional. Porto Alegre: Artes Médicas Sul, 1999.

GONZÁLEZ MANJÓN, Daniel. Adaptaciones curriculares. Guía para su elaboración. Málaga: Aljibe, 1993.

GONÇALVES, Luiz Alberto O; SILVA, Petronilha B. G. O Jogo das diferenças: o multiculturalismo e seus contextos. Belo Horizonte: Autêntica, 1998.

HALL, Stuart. A identidade cultural na pós-modernidade. Trad. Tomaz Tadeu da Silva e Guacira Lopes Louro. 7. ed. Rio de Janeiro: DP\&A, 2003.

. Da Diáspora. Identidades e Mediações Culturais. Tradução: Adelaine La Guardia Resende et al. Belo Horizonte: Editora UFMG; Brasília: Representação da UNESCO no Brasil, 2003a.

MCLAREN, Peter. Multiculturalismo crítico. 3. ed. São Paulo: Cortez; Instituto Paulo Freire, 2000.

A Vida nas Escolas: uma introdução à pedagogia crítica nos fundamentos da educação. Porto Alegre: Artes Médicas, 1997.

MELO, Marcus André. Estado, governo e políticas públicas. In: MICELI, Sérgio (Org.). O Que ler na ciência social brasileira: ciência política. 3. ed. São Paulo: Sumaré; Anpocs; Capes, 1999. p. 59-100.

MOEHLECKE, Sabrina. As políticas de diversidade na educação no governo Lula. Cad. Pesqui., São Paulo, v. 39, n. 137, ago. 2009. Disponível em: <http://www.scielo.br/scielo.php?script=sci_arttext\&pid=S010015742009000200008\&lng=en\&nrm=iso $>$. Acesso em: 19 jul. 2010. 
MORAES, Maria Cândida. Educar na biologia do amor e da solidariedade. Petrópolis: Vozes, 2003.

MOREIRA, Antonio. Flávio; SILVA, Tomaz Tadeu. Cultura popular e pedagogia crítica: a vida cotidiana como base para o conhecimento curricular. In: (Orgs.). Currículo, cultura e sociedade.

7. ed. São Paulo: Cortez, 2002.

MUÑOZ SEDANO, Antonio. Educación Intercultural: teoria y practica. Madrid: Escuela Española, 1997.

NANNI, Antonio. L'educazione interculturale oggi in Italia. Brescia: EMI, 1998.

PADILHA, Paulo Roberto. Currículo intertranscultural: novos itinerários para a educação. São Paulo: Cortez, 2004.

SANSONE, Livio. Racismo sem etnicidade. Políticas públicas e discriminação racial em perspectiva comparada. DADOS: Revista de Ciências Sociais, Rio de Janeiro, v. 41, n. 4, p. 751-783, 1998.

SCHERER-WARREN, Ilse. Movimentos sociais e a dimensão intercultural. In: FLEURI, Reinaldo M. (Org.). Intercultura e Movimentos Sociais. Florianópolis: MOVER; NUP, 1998. p. 31-32.

. Movimentos em cena... as teorias por onde andam? In: SCHERER-WARREN, Ilse et al. Cidadania e Multiculturalismo: a teoria social no Brasil contemporâneo. Lisboa/Florianópolis: Socius/ Editora da UFSC, 2000. p. 23-51.

STOER, Sthepen R. Desocultando o vôo das andorinhas: educação inter/multicultural crítica como movimento social. In: et al. (Orgs.). A transnacionalização da educação: da crise da educação à educação da Crise. Porto: Afrontamento, 2001. p. 165-210.

TAYLOR, Charles. La ética de la autenticidad. Barcelona: Paidos, 1994.

TORRES, Carlos Alberto. Democracy, Education and Muticulturalism: dillemas of citizenship in a global world. Lanham. Nova Iorque: Oxford. Rowman \& Littlefield Publ, 1998. 
TOURAINE, Alaine. Podemos viver juntos? Iguais e diferentes. Trad. Jaime A. Clasen e Ephraim F. Alves. Rio de Janeiro: Vozes, 1998.

VIEIRA, Ricardo. Ser inter/multicultural. Jornal A página da educação, Portugal, ano 8, n. 78, mar. 1999. Disponível em: <http://www.a-paginada-educacao.pt/>. Acesso em: 10 jan. 2007.

WALSH, Catherine. Interculturalidad y (de)colonialidad: Perspectivas críticas y políticas. Congresso da Association Internationale Pour la Recherche Interculturrele (ARIC), 12., 2009, Florianópolis. Diálogos interculturais: Descolonizar o saber e o poder. Florianópolis: UFSC (www.aric2009.ufsc.br, 2009). Disponível em: <http://aric.edugraf.ufsc. br/congrio/anais/artigo/767/textoCompleto>. Acesso em: 20 set. 2009.

Notas

* O presente artigo faz parte do Capítulo III da tese de doutorado intitulada Educação e sensibilidade: possibilidades para a docência aprovada em sua forma final em abril de 2012, pelo Programa de Pós-graduação em Educação da Universidade Federal de Santa Catarina (UFSC), sob a orientação do prof. Dr. Reinaldo Matias Fleuri e a co-orientação da prof ${ }^{\mathrm{a}} \mathrm{Dr}^{\mathrm{a}}$. Tania Stoltz.

** Doutora em Educação e professora adjunta da Faculdade de Ciências Humanas e da Educação da Universidade do Estado de Santa Catarina (Udesc). E-mail: <coppetemaria@gmail.com>.

*** Doutor em Educação e pós-doutor pela Università degli Studi di Perugia, Itália (1996), pela Universidade de São Paulo (2004) e pela Universidade Federal Fluminense (2010). Professor titular da Universidade Federal de Santa Catarina, com vínculo de professor voluntário após sua aposentadoria em 2011. É professor visitante Nacional Sênior (CAPES) junto ao Instituto Federal Catarinense desde 2012. Coordena o Grupo de Pesquisa Educação Intercultural e Movimentos Sociais (UFSC/CNPq). E-mail: <fleuri@pq.cnpq.br>.

**** Doutora em Educação e pós-doutora pelos Archives Jean Piaget, em Genebra, Suíça (2007), e pela Alanus Hochschule, Alemanha (2012). Professora com dedicação exclusiva na Universidade Federal do Paraná, atualmente como Associado II. E-mail: <tania.stoltz795@googlemail.com>.

${ }^{1}$ Paola Falteri é doutora em antropologia; professora pesquisadora no Instituto di Etnologia e Antropologia Culturale da Università di Perúglia (Itália). É sóciafundadora da Sociedade Italiana de Antropologia Médica (SIAM) e publicou vários artigos sobre o assunto. Dedica-se à antropologia da educação desde 1975, trabalhando com o Movimento di Cooperazione Educativa, junto ao 
qual coordenou o grupo Nacional de Antropologia, até 1985. É assessora da escola de formação intercultural. Tem um conjunto expressivo de publicações, dentre as quais destaca-se: Andata e ritorni: Percosi formativi interculturali. Firenze:MCE/Ministero della Publica Istruzione, 1995. Para consultar essas informações e saber mais, cf.: FLEURI, R. M. (Org.). Intercultura e Movimentos Sociais. Florianópolis: Mover; NUP, 1998. p. 209-210.

2 MOVER: Núcleo de Estudos "Educação Intercultural e Movimentos Sociais" do Centro de Ciências da Educação da Universidade Federal de Santa Catarina, que desenvolve pesquisas no âmbito da cultura e da educação popular. Ver site $<$ www.mover.ufsc.br> e diretório de Grupos do CNPq <http://dgp.cnpq.br/ buscaoperacional/detalhegrupo.jsp?grupo=0043708JCBVE0N $>$.

${ }^{3}$ O Projeto Integrado de Pesquisa Educação Intercultural: elaboração de referenciais epistemológicos, teóricos e pedagógicos para práticas educativas escolares e populares contou com o apoio do CNPq tendo como referência a Bolsa de Produtividade em Pesquisa - PQ, Prof. Dr. Reinaldo Matias Fleuri (processo CNPq n. 304741/2003-5) com vigência de março de 2004 a fevereiro de 2007. A esse projeto vincularam-se duas Bolsas de Iniciação Científica, pelo (Processo CNPQ n. 501800/2004-2 Edital: 052004-IC, com vigência de agosto de 2004 a julho de 2007) e uma Bolsa de Apoio técnico (processo CNPq n.: 361651/2004-0, com vigência de agosto de 2004 a julho de 2006). Contou, também, com Auxílio à Pesquisa (processo 473965/2003-8, Edital Universal CNPq 01/2002, Faixa B, com vigência de 28 out. 2003 a 28 out. 2005). Destacase também o projeto de pesquisa Educação Intercultural: desconstrução de subalternidades em práticas educativas escolares e populares, cuja vigência abrangeu o período de março de 2007 a fevereiro de 2010. O referido projeto tem como objetivos conceituar epistemologicamente a perspectiva intercultural da educação, focalizando no contexto brasileiro e latino-americano as relações de identidade e diferença que se desenvolvem em movimentos sociais, particularmente no âmbito das relações entre culturas étnicas, geracionais e de gênero, visando à elaboração de subsídios teórico-metodológicos para a formação de educadores, assim como para a educação popular e escolar. Cabe destacar, por um lado, como campo empírico do trabalho do grupo, a realização de cursos de formação de educadores na perspectiva intercultural, fortemente enraizados na realidade local e regional, que constituem com um campo de interação e integração, por outro lado, entre os diferentes projetos de pesquisas assumidos, seja por estudantes do PGE/UFSC vinculados atualmente ao grupo, seja por pesquisadores do mesmo grupo vinculados a outras instituições, seja por outros grupos de pesquisa parceiros nacionais e internacionais que interagem na rede de pesquisas sobre educação intercultural. É apoiado pelo CNPq em várias modalidades de bolsas de estudo e de auxílio: (1.) Bolsa de Produtividade em Pesquisa - PQ, Prof. Dr. Reinaldo Matias Fleuri, processo CNPq n. 304741/2003-5, com vigência de março de 2004 a fevereiro de 2007 (valor: R\$ 35.179,92). (2.) Bolsas de Iniciação Científica: Processo CNPQ n. 501800/2004-2 Edital: 052004-IC. É importante destacar que nesses 15 anos 
de existência do grupo Mover, as ações de pesquisa realizadas têm resultado também em valiosos programas, variados cursos de formação experimental de educadores, intensas atividades de cooperação interinstitucionais, uma vastíssima produção bibliográfica, bem como de material pedagógico impresso, digital e áudio-visual, além de profícuos eventos, dentre os quais se pode destacar: II Seminário Internacional Educação Intercultural, Gênero e Movimentos Sociais (Florianópolis, 8-11 abr. 2003); III Seminário Internacional Educação intercultural, Movimentos Sociais e Sustentabilidade (Florianópolis, 13-17 nov. 2006); de modo particular, vem se consolidando a interação com a Association Internationelle pour la Recherche Interculturelle (ARIC), de cujo Conselho Administrativo Reinaldo Matias Fleuri passou a fazer parte em 2005. No ano de 2009, foi eleito presidente da referida associação, trazendo para o Brasil (pela primeira vez no território latino-americano) o XII Congresso da Association pour la Recherche Interculturell (ARIC), realizado em julho/agosto de 2009. Para saber mais sobre todas as informações citadas, conferir <www.mover. ufsc.br>.

${ }^{4}$ Para saber mais, consultar: <www.aric2009.ufsc.br>.

${ }^{5}$ Nesse sentido, é possível citar duas importantes experiências das quais participei diretamente como consultora em dois municípios do estado de Santa Catarina. A primeira delas foi realizada na cidade de Paulo Lopes, em parceria com a prof ${ }^{a}$ Marlene Zwierewicz. O objetivo consistiu em um processo de formação continuada de professores da rede municipal que culminou com a elaboração da Proposta Curricular da rede municipal de educação lançada na gestão do governo que compreendeu o período de 2001 a 2008. Os eixos norteadores do processo educacional foram a Atenção à Diversidade, Educação Ambiental, Inclusão Digital e o Ensino e Aprendizagem pela Pesquisa. $\mathrm{Na}$ experiência realizada na rede municipal de educação de Criciúma, a coordenação pedagógica para elaboração da Proposta Curricular foi realizada em parceria com a prof ${ }^{\mathrm{a}} \mathrm{Dr}^{\mathrm{a}}$. Geovana Lunardi, prof. Dr. Lourival José da Silva Filho e prof ${ }^{a}$ Me. Neli Góes Ribeiro que assim como eu são docentes efetivos da Faculdade de Ciências e Educação - FAED na Universidade do Estado de Santa Catarina (UDESC); nessa experiência, também consolidada no ano de 2008, contamos com o apoio de uma equipe de consultores por área de conhecimento. A proposta foi intitulada: Currículo para a Diversidade: sentidos e práticas. Para acessar a equipe de trabalho, cf.: <http://www.criciuma.sc.gov.br/uploaded/ educacao/parte1.pdf $>$. Para consultar a proposta na íntegra, cf.: <http://www. criciuma.sc.gov.br/conteudo.php?codigo $=163 \&$ secretaria $=10>$.

${ }^{6}$ Cf.: Hall (2003a) e Canclini $(1995,1997)$.

${ }^{7} \mathrm{O}$ sentido de pertencimentos e identidade são tomados neste estudo a partir de Serres (1999). Para o autor a identidade de uma pessoa é a intersecção de todos os seus pertencimentos. Para tanto, usa alguns exemplos: "[...] fazemos sempre graves confusões sobre a noção de identidade. Não me agrada que as pessoas falem em 'identidade sexual,' 'identidade nacional,' 'identidade cultural' etc.. Por quê? Porque elas confundem identidade com pertencimento. Assim, quando 
falam, por exemplo, em identidade brasileira, identidade francesa, confundem o que seja identidade - identidade é 'A' idêntico a 'A', isto é, 'Michel Serres' é idêntico a 'Michel Serres': isto é a identidade. O fato que eu seja francês... Isso não é a minha identidade, isso é meu pertencimento. $O$ fato que eu seja judeu, católico, protestante... Pertencimento. O fato que eu me chame Serres é, aliás, um pertencimento a uma família. $\mathrm{O}$ fato que eu me chame Michel é pertencimento ao conjunto de pessoas que se chamam Michel. Tudo isso são pertencimentos. E, por conseqüência, confundir pertencimento com identidade é a própria definição de racismo. Porque se diz: ele é negro, ele é judeu, ele é católico, ele é... Não! Ele é Michel Serres. A identidade não deve ser confundida com pertencimento. Uma coisa é: A = A ('A' idêntico a 'A'); outra coisa é: A pertence ao conjunto 'A'. [...] é verdade que várias pessoas confundem sua identidade com seu pertencimento e se relacionam com os outros em nome de algo que é apenas um pertencimento e não sua identidade... [...] É preciso ensiná-las de que se trata apenas de um pertencimento. Mas podemos ir mais longe e dizer: 'qual é sua identidade?' Bem, minha identidade é a intersecção de todos os meus pertencimentos. Eu sou brasileiro + moreno + filósofo + médico $+\ldots+$ ... + ... e mais eu tenho pertencimentos, mais eu enriqueço minha identidade." Para saber mais, cf.: <http://www.scielo.br/scielo.php?script=sci_arttext\&pid $=$ S1414-32832000000100013>. 